\title{
O SURGIMENTO DO ESTADO REPUBLICANO 1
}

\author{
LUIZ CARLOS BRESSER-PEREIRA
}

A necessidade cada vez maior de um Estado forte e legítimo nasceu, por um lado, das crescentes demandas da sociedade e, por outro, do surgimento do sistema global. O novo Estado que está emergindo precisa ser um Estado liberal, democrático e social forte. Um Estado liberal forte garante os direitos civis que protegem a vida, a propriedade e a liberdade, e assegura que cada cidadão seja tratado com respeito, independentemente de riqueza, sexo, raça ou cultura. Um Estado democrático forte garante os direitos políticos a todos os cidadãos, considerando cada um como igual aos outros. Um Estado social forte garante os direitos sociais, combatendo o desemprego e a desigualdade econômica. Mas, para ser forte com relação aos três direitos humanos clássicos, o Estado precisa ser capaz de garantir os direitos republicanos, e contar com cidadãos que participem ativamente dos assuntos políticos. Em outras palavras, o Estado precisa ser republicano.

O Estado republicano é um Estado suficientemente forte para se proteger da captura privada, defendendo o patrimônio público contra a busca de rendas (rent-seeking); é um Estado participativo, onde os cidadãos, organizados em sociedade civil, participam da definição de novas políticas e instituições e do exercício da responsabilidade social; é um Estado que depende de funcionários governamentais que, embora motivados por interesse próprio, estão também comprometidos com o interesse público; é um Estado com uma capacidade efetiva de reformar instituições e fazer cumprir a lei; é um Estado dotado da legitimidade necessária para taxar os cidadãos a fim de financiar ações coletivas decididas democraticamente; é um Estado que é eficaz e eficiente no desempenho dos papéis

1 Trabalho apresentado no III Simpósio Internacional sobre Justiça, Porto Alegre, 1-5 de setembro de 2003. Revisado em fevereiro de 2004. 
dele exigidos. Resumindo, o Estado republicano é um sistema de governo que conta com cidadãos engajados, participando do governo juntamente com os políticos e os servidores públicos.

Essa definição do Estado republicano está relacionada com a tradição republicana clássica, mas não afirmo que seja fiel a ela. As repúblicas grega e romana eram uma realidade e um ideal. As repúblicas italianas dos séculos XIV e XV também eram consideradas ideais. Os republicanos do século XVIII basearam suas próprias visões nas anteriores. O Estado republicano do século XXI será necessariamente uma realidade diferente, que exige novos conceitos e novas considerações teóricas, e que envolve valores ou ideologias específicos.

O Estado republicano é viável no contexto de uma sociedade civil ativa na qual são observados os princípios da democracia liberal, social e participativa ou deliberativa. Os Estados republicanos diferirão de um país para outro, refletindo sua história e sua cultura, mas compartilharão alguns valores e instituições básicos e comuns. Estamos nos encaminhando para Estados republicanos? Acredito que sim. Desde o surgimento do Estado moderno, os sistemas de governo democráticos vêm progredindo: não linearmente, não seguindo um padrão constante, mas através de altos e baixos, avanços significativos e, às vezes, trágicas regressões. Países avançados contam hoje em dia com instituições mais eficazes em tornar os políticos e os funcionários burocráticos mais responsáveis e em proteger o Estado contra sua captura ou a busca de rendas (rent-seeking); por outro lado, contam com cidadãos mais educados e participativos. Os direitos republicanos, embora constantemente violados, são atualmente mais bem definidos e protegidos. As reformas institucionais, e particularmente a reforma da gestão pública, estão avançando em toda parte, o que significa que o Estado está se tornando mais capaz. A recente onda ultra-liberal representou um importante desafio e levou à necessária reforma do Estado, mas, considerando que seu objetivo era enfraquecer o Estado, fracassou e desapareceu. Assim, acredito que a oportunidade de continuar construindo o Estado republicano é hoje uma realidade.

$\mathrm{Na}$ análise a seguir estarão presentes um aspecto empírico e um aspecto normativo. De uma perspectiva histórica, acredito que seja razoável prever a gradual ascensão do Estado republicano; de uma perspectiva normativa, espero que isso aconteça. Essa linha normativa não conflita com a linha histórica. Ao contrário, elas se reforçam mutuamente. Desenvolvimentos históricos apontam nessa direção, e os desafios que a ação coletiva enfrenta atualmente exigem que instituições sejam inven- 
tadas e reformadas, a fim de se manterem condizentes com esse tipo de Estado. Eu vejo as coisas dessa maneira, apesar de todos os problemas que as democracias avançadas enfrentam hoje em dia. Elas estão maduras para o surgimento do Estado republicano, e é portanto hora de discutir como ele acontecerá.

Os mesmos fatores que geraram o Estado social-liberal - a crise do Estado social-democrata, a revolução da informática, a globalização e a equivocada resposta ultra-liberal a tais fenômenos - estão nos bastidores do surgimento do Estado republicano. O Estado social-liberal e o Estado republicano são a mesma coisa. No entanto, quando falo de Estado republicano estou me referindo à capacidade do Estado não apenas de garantir direitos civis, políticos e sociais, mas também de garantir direitos republicanos e, ao fazer isso, de se proteger do controle privado. O conceito de um Estado republicano refere-se ao surgimento de direitos republicanos e ao reaparecimento do republicanismo.

Nos últimos vinte e cinco anos do século XX, quando os direitos republicanos adquiriram importância histórica, enquanto as organizações da sociedade civil ganhavam relevância nacional e internacional, tornou-se óbvio que o desafio político básico era construir um Estado capaz de se proteger de indivíduos ou corporações ambiciosos e poderosos, e ao mesmo tempo com capacidade de organizar a ação coletiva para garantir os direitos de cidadania. Por outro lado, depois que a ofensiva ultra-liberal demonstrou ser incapaz de eliminar ou mesmo reduzir os direitos sociais, os Estados se tornaram mais fortes politicamente, o que, no entanto, não significou uma volta ao modelo socialdemocrata. Tornou-se cada vez mais claro que tal modelo havia sido uma reação excessiva ao Estado liberal clássico, que mercados livres eram uma ferramenta extraordinariamente poderosa de promoção da riqueza e de garantia de liberdade quando devidamente regulados pelo Estado. Assim, uma solução intermediária tinha agora sua vez. Em lugar de um compromisso entre valores liberais e direitos sociais, tornou-se ainda mais óbvio que somente um Estado forte poderia garantir mercados fortes. Também está ficando evidente que os cidadãos que têm seus direitos sociais cuidadosamente protegidos comportam-se mais livre e ativamente nos mercados do que aqueles que não são tão protegidos. Examino aqui o Estado social-liberal que deriva dessa combinação de Estado e mercados, da busca individual de autonomia pessoal e das demandas dos cidadãos por uma seguridade social cada vez mais abrangente ou pela proteção dos direitos sociais. 
A fim de aumentar a capacidade do Estado e construir o Estado republicano, as sociedades modernas terão de contar com políticos, servidores públicos e cidadãos que estejam prontos a participar do processo político, dotados de patriotismo ou virtudes cívicas. Embora a preocupação com a proteção da res publica e a participação cívica sejam fenômenos antigos, eles só se disseminaram - como uma preocupação do povo e não unicamente das elites - nos últimos vinte e cinco anos do século XX. Ao mesmo tempo, o Estado social-democrata entrou em crise e as reformas orientadas para o mercado se tornaram um aspecto central da globalização. Os mercados, cujo papel na alocação de recursos havia sido reduzido durante a era do Estado social-democrata, ganharam uma nova primazia mas não tanto quanto os neoliberais esperavam. Os direitos sociais, que sofreram um severo ataque durante a onda neoliberal, terminaram sendo reafirmados em quase todos os países, na medida em que a sociedade civil rejeitou as propostas de um Estado mínimo. Ao contrário, ampliou-se o papel do Estado em garantir mercados competitivos, liberdade e justiça social. Em lugar de forçar sua organização a retornar à administração pública burocrática, de maneira condizente com o Estado liberal, ou às enormes burocracias sociais desenvolvidas pelo Estado social-democrata, o Estado se envolveu na reforma da gestão pública. E tudo isso é possível na medida em que os cidadãos, organizados em sociedade civil, estão se mostrando capazes de participar efetivamente dos assuntos públicos e de esboçar a estrutura de uma democracia participativa e republicana.

Estou dizendo que o Estado republicano será democrático, liberal e social; no entanto, sabemos que os ideais republicanos, liberais, democráticos e socialistas estiveram historicamente em conflito mútuo. Embora os ideais liberais e democráticos tenham entrado em choque no início do século XIX, eles acabaram se tornando compatíveis quando liberais e democratas abandonaram suas visões radicais. Na medida em que definimos liberalismo como a afirmação dos direitos civis, da liberdade individual e dos direitos de propriedade, da tolerância e do pluralismo, e definimos socialismo como a proteção efetiva dos direitos sociais com uma preocupação central com a justiça social, ambos podem ser compatíveis. Começarei reconhecendo o clássico conflito entre ideais republicanos e liberais, e entre ideais republicanos e democráticos, mas concluirei mais uma vez que eles podem se tornar e estão se tornando compatíveis, desde que tais ideais não sejam adotados de modo radical. Mais do que isso: eu direi que ao Estado republicano moderno corresponde uma forma mais avançada de democracia representativa, a saber, a democracia participativa ou deliberativa. 


\section{IDEAIS REPUBLICANOS}

Os ideais republicanos e humanistas remontam às repúblicas grega e romana. Esta não é a ocasião para uma pesquisa sobre republicanismo. O humanismo cívico ou os valores cívicos republicanos surgiram em Roma, com Cícero; reapareceram nas repúblicas do Norte da Itália do quatrocento, com Bruni; tiveram sua primeira afirmação 'moderna' com Maquiavel; chegaram à França com Montesquieu, à Inglaterra com Harrington, e aos Estados Unidos com Madison. Uma vez que o republicanismo precedeu o liberalismo, os teóricos da política muitas vezes encaram os valores e deveres republicanos como alternativas aos liberais, embora eles na verdade se complementem, como nos ensinam os historiadores das idéias, como J. G. A. Pocock (1975) e Quentin Skinner (1978, 1998), ou os filósofos políticos, como Philip Pettit (1997), Richard Dagger (1997) e Newton Bignotto (2001). O republicanismo enfatiza os deveres e a participação política dos cidadãos, e se baseia nas virtudes cívicas exigidas dos cidadãos, enquanto o liberalismo salienta os direitos e se baseia nas liberdades negativas dos cidadãos motivados por interesse próprio. No entanto, da mesma forma que não vejo qualquer conflito necessário entre direitos civis e sociais ou entre ideais liberais e socialistas, também não vejo nenhuma inconsistência absoluta entre direitos civis e virtudes cívicas ou entre liberdade negativa e positiva.

Historicamente, tais valores e as correntes políticas a eles subjacentes entraram em choque, mas nas democracias contemporâneas avançadas estamos aprendendo a integrar valores, a chegar a compromissos ou, mais do que isso, a quase-consensos. A mudança do Estado liberal para o Estado social-democrata e finalmente para o Estado social-liberal e republicano é um processo de desenvolvimento político através do qual os direitos do cidadão foram sendo cada vez mais garantidos.

É digno de nota que o filósofo político que discutiu mais profundamente o social-liberalismo - Norberto Bobbio - nunca tenha sido atraído pelo republicanismo. Para ele, "a república dos republicanos é uma forma de Estado ideal, um "modelo moral" como foi chamada na república de Montesquieu, que influenciou os revolucionários franceses: um Estado ideal que não existe em nenhum lugar". Acompanhando a maioria dos liberais, ele se denomina um 'realista' em política: "Em política, sou um realista. Só é possível falar de política se se mantiver um olhar frio sobre a história. A política, monárquica ou republicana, é a luta pelo poder" (Bobbio e Viroli 2001: 7-8). No entanto, não acredito que seja necessário 
ser um idealista para reconhecer o surgimento do Estado republicano. Basta ter claro que o Estado republicano não é o Estado ideal; é apenas uma forma superior de democracia social e liberal. Não é o Estado formado por cidadãos virtuosos, mas o Estado em que os valores cívicos são importantes. Não é o Estado que elimina a corrupção e o rentismo, mas desenvolve armas eficazes para se proteger de tais ameaças. Como o Estado republicano garante os direitos republicanos, é capaz de se proteger. Desse modo, o círculo é fechado.

No passado, quando o liberalismo se opôs aos ideais democráticos e exigiu um Estado autoritário para proteger as liberdades individuais, ele imaginava um Estado todo-poderoso e indivíduos indefesos; agora, quando o republicanismo exige proteção para a res publica, o pressuposto é o inverso. No entanto, em ambos os casos, a combinação de interesse próprio e interesse público é essencial. Sem uma noção razoavelmente clara de interesse público, é impossível definir a res publica. Em geral, res publica é o bem público; em um sentido mais restrito, é o patrimônio público. $^{2}$ Sem uma perspectiva republicana é difícil defender o patrimônio público. Se os cidadãos carecem de noções claras do espaço público e do bem comum ou interesse público, a defesa do patrimônio público igualmente não oferece perspectivas. Como um conceito mais geral do espaço público, a res publica ou 'o público' inclui tudo aquilo que é público, que pertence ao povo, que é de e para todos, que é manifesto e portanto dotado de publicidade, que é garantido ou assegurado mediante uma legislação pública. ${ }^{3}$ Como uma corporificação do bem comum ou do interesse público, a res publica assume um caráter normativo. Quando as pessoas, em lugar de serem meros observadores, ampliam seu compromisso com o bem comum ou com o interesse público, elas se tornam cidadãos melhores. ${ }^{4} \mathrm{Na}$ verdade, é impossível defender o patrimônio público se não há república, se os cidadãos não compreendem claramente a noção de espaço público, de bem comum ou de interesse público.

A identificação da res publica com o aparelho do Estado é enganosa. O patrimônio público inclui mais do que aquilo que é detido

\footnotetext{
${ }^{2}$ É possível também pensar a res publica em termos de um regime político - o sistema republicano - ou em termos do próprio Estado.

${ }^{3}$ Ver a análise de Smend (1934) sobre o problema do público e da coisa pública.

4 De acordo com Janine Ribeiro (1994: 34), "quanto mais os cidadãos forem reduzidos a público, a espectadores das decisões políticas, menor será o caráter público das políticas adotadas, menor o seu compromisso com o bem comum, com a res publica que deu nome ao regime republicano".
} 
pelo Estado, enquanto tudo o que é detido pelo Estado é apenas nominalmente público; na prática, parte dele pode ser apropriada por interesses privados. O patrimônio econômico público pode ser definido como o estoque de ativos públicos, mas é também, e principalmente, o fluxo de recursos públicos - receitas de impostos, de um lado, e despesas, de outro. Receitas e despesas de organizações públicas não estatais também devem ser incluídas. Este fluxo de recursos é mais vulnerável do que o estoque de ativos públicos porque é mais facilmente sujeito à apropriação privada. No século XX, enquanto o Estado e as organizações públicas não estatais floresciam, o primeiro em termos de seu poder de taxar, as demais mediante contribuições voluntárias, a pura cobiça e conseqüente competição de grupos de interesse por tais recursos também explodiu. Assim, a proteção da res publica, que já era importante anteriormente, tornou-se imperativa. ${ }^{5}$ No Estado republicano, a preocupação com a proteção do interesse público e do patrimônio público é primordial. Tendo em vista os interesses conflitantes que existem em toda sociedade, nem sempre o interesse público será evidente. A governança democrática é o processo principal através do qual os modernos sistemas de governo definem, para cada questão, qual é o interesse público. Assim, o Estado republicano é intrinsecamente democrático. Mas é mais do que democrático porque, assim como é capaz de proteger cidadãos individuais, é igualmente capaz de se proteger dos interesses conflitantes: ele possui as instituições e os cidadãos que ajudam a promover essa proteção.

\section{REPUBLICANISMO E LIBERALISMO}

Do ponto de vista da teoria política, tornar compatíveis liberalismo e republicanismo não é tarefa simples. Primeiro, temos de ter em mente que o liberalismo é muitas vezes identificado com liberalismo econômico. Enquanto o liberalismo econômico tende a enfatizar o interesse próprio e a ser conservador, o liberalismo político tende a ser progressista,

\footnotetext{
5 Não há estimativa desse fluxo de recursos se incluirmos as receitas de entidades públicas não estatais. No entanto, se levarmos em conta apenas a carga tributária, sabemos que, nos países desenvolvidos, ela cresceu de cerca de 5-10\% no início do século XX para cerca de $30-50 \%$ do PIB nos dias atuais. Na verdade, as isenções fiscais que beneficiam certos grupos deveriam ser incluídas no conceito de res publica. Sua inclusão se justifica na medida em que a receita que o Estado não recolhe não beneficia o conjunto da sociedade, não corresponde a uma redução geral de impostos, mas a um benefício para certos grupos.
} 
pronto para colocar em risco a ordem em nome da justiça social, e dá ênfase à solidariedade. Sérgio Costa (2002: 22) observa que a cidadania moderna se caracteriza pela cidadania econômica definida em termos de direitos de propriedade e contratos, e pela cidadania política definida em termos do direito de participar. Essas duas dimensões têm como protótipos as figuras do bourgeois e do citoyen; e não é do primeiro, que é parte de um "sistema de necessidades", que se pode esperar ações virtuosas. É somente a partir da dimensão política, na esfera pública, que se pode esperar encontrar cidadãos virtuosos. Podemos ter capitalistas virtuosos, mas quando eles o são, estão agindo de acordo com a lógica da cidadania, não de acordo com a lógica do mercado. O liberalismo, enquanto originalmente uma ideologia burguesa, está interessado na proteção das liberdades; o liberalismo econômico, na garantia dos direitos de propriedade e dos contratos; o liberalismo político, na igualdade de todos os cidadãos e na liberdade individual. É difícil reconciliar o republicanismo com o liberalismo puramente econômico, enquanto o liberalismo político é compatível com a tradição republicana.

Em segundo lugar, temos de levar em conta os dois conceitos de liberdade. Enquanto a tradição liberal considera a liberdade como "negativa", no sentido de que o Estado não deveria interferir na liberdade e na propriedade dos cidadãos exceto para evitar dano à sociedade, e tem uma concepção limitada dos direitos dos cidadãos, o republicanismo vê a liberdade como "positiva" e tem, portanto, uma concepção mais ampla dos direitos humanos. Conceitualmente, a liberdade tem dois lados: o conceito negativo, que está associado aos direitos civis e ao liberalismo, e o conceito positivo, que está associado à democracia no caso dos direitos políticos, ao socialismo no caso dos direitos sociais, e à cidadania plena no caso dos direitos republicanos. Liberdade negativa é "estar livre de", enquanto liberdade positiva é "estar livre para". Os cidadãos têm a liberdade negativa de não estarem sujeitos a restrições ou interferências em seus legítimos desejos ou interesses; têm a liberdade positiva de participar do governo, compartilhar do bem público ou comum, e resistir às tentativas de indivíduos particulares de se apoderarem do patrimônio público. Para ser coerente apenas com o conceito negativo de liberdade, é preciso rejeitar a idéia de que o Estado deve estar orientado para o bem comum.

Essa distinção entre liberdade negativa e positiva deve sua formulação contemporânea a Isaiah Berlin. ${ }^{6}$ Berlin escreveu seu ensaio sobre

\footnotetext{
${ }^{6}$ Berlin (1958). A formulação clássica dessa distinção foi feita por Constant (1814). Na Parte II, Capítulo VI, de De L'Esprit de Conquête et de l'Usurpation, ele escreve sobre "la liberté des anciens et la liberté des modernes".
} 
os dois conceitos de liberdade no auge do conflito ideológico entre liberais e marxistas. Embora tivesse consciência das compensações entre os dois tipos de liberdade, ele valorizava a liberdade negativa e enfatizava os riscos da liberdade positiva, que é "por vezes, não mais que um disfarce capcioso para a tirania brutal" (Berlin 1958: 131). Como um liberal clássico - e ciente do fato de que o liberalismo floresceu no século XVII - ele estava preocupado em limitar o poder de governos que, em princípio, são autoritários. Em contraste com a visão liberal, a tradição republicana adota um conceito positivo de liberdade. O povo, na antiga democracia ateniense e na república romana, era composto de cidadãos, não apenas indivíduos, e não era oprimido por um monarca absoluto como eram os modernos - os liberais - de Benjamin Constant. O conceito de liberdade de Berlin como sendo a ausência de algum elemento de restrição que iniba o indivíduo de agir na busca dos objetivos que escolheu tem sua origem em Hobbes. Na sua teoria contratual do Estado, que mais tarde seria adotada pelos liberais, Hobbes presume o Estado de natureza, a guerra de todos contra todos, e a partir daí deduz - seu método é essencialmente hipotético-dedutivo - o conceito de liberdade como ausência de restrição. Em contraste, teorias positivas de liberdade têm sua origem em Aristóteles, que parte do pressuposto que o homem é essencialmente um ser moral, um animal político. Dessas premissas, só se pode derivar um conceito positivo de liberdade. E rejeitar, como fazem tantos liberais modernos adeptos da escolha racional, a idéia de bem comum. No entanto, John Locke, que pode ser visto como o fundador do liberalismo, não teve dificuldade em adotar um conceito negativo de liberdade ("liberdade é estar livre da restrição e da violência dos outros") e em enfatizar que a condição para que tal liberdade seja assegurada é que as leis sejam orientadas para o bem comum. Em suas palavras:

Os homens, quando se constituem em sociedade, renunciam à igualdade, à liberdade e ao poder executivo que tinham no Estado de natureza em favor da sociedade, para serem regulados pelo legislativo até onde o bem da sociedade exigir; no entanto[...] a sociedade ou o legislativo constituído por eles nunca pode pretender se estender além do bem comum. ${ }^{7}$

7 Locke (1690: \#57; \#131). Observem que Locke aqui usa "sociedade" em lugar de Estado. Na maior parte do livro ele usa "sociedade civil", "sociedade política" e "commonwealth" [comunidade civil] para significar Estado. Às vezes Locke utiliza a palavra "governo" com esse mesmo sentido, como se faz freqüentemente na teoria política anglo-americana, mas na maior parte das vezes ele atribui a essa expressão o mesmo sentido que estou lhe dando: o grupo de pessoas que governa, ou o processo de governar. 
Skinner distingue duas versões do republicanismo contemporâneo. De um lado, temos autores como Skinner, que acredita que a participação política é uma condição para garantir a liberdade pessoal; de outro lado, Charles Taylor, que associa governo a autogoverno: só seremos realmente livres se estivermos comprometidos com o serviço público. Para Skinner, os liberais não fazem a distinção adequada entre corrupção e honestidade, na medida em que abraçam o conceito da mão invisível. Os interesses são legítimos, mas dos interesses se inferem deveres e virtudes, como coragem e prudência, não apenas interesse próprio. Skinner observa que o perigo da restrição ou coerção políticas apontado pelos liberais é real, mas disso não se segue que seja necessária ou aconselhável uma atitude negativa em relação à liberdade. Ao contrário, a ação positiva dos cidadãos dotados de virtude cívica é necessária para proteger a liberdade e é uma condição para que um indivíduo esteja total ou verdadeiramente em liberdade. Em suas palavras:

A manutenção de nossos deveres públicos é indispensável para a manutenção de nossa própria liberdade. Se é verdade, no entanto, que a liberdade depende de serviço, e portanto de nossa disposição de cultivar as virtudes cívicas, segue-se que podemos ter de ser coagidos à virtude e, desse modo, compelidos a sustentar uma liberdade que, se fosse deixada unicamente a nosso cargo, teríamos minado. ${ }^{8}$

Aqui Skinner demonstra ser um republicano, embora um "republicano na defensiva". Os cidadãos precisam agir positivamente a fim de proteger sua própria liberdade. Como os liberais, ele preferiria que a liberdade pudesse ser apenas a ausência de restrição, mas percebe que a liberdade precisa ser conquistada e defendida. Em outras palavras, a liberdade positiva ou republicana implica uma participação efetiva de cada cidadão nos assuntos públicos. Em contraste, o republicanismo de Philip Pettit não é tão claro. Ele distingue não duas, mas três formas de liberdade. Ele segue Isaiah Berlin ao reconhecer que a liberdade positiva é o domínio sobre si mesmo, e a liberdade negativa, a ausência de interferência. Mas acrescenta uma terceira forma, que chama de republicana: a ausência de dominação. Ele encara essa não-dominação como liberdade real, e descarta a participação política como um elemento essencial da liberdade positiva republicana. Assim, adota praticamente um conceito negativo de liberdade. Ele vê uma diferença primordial

${ }^{8}$ Skinner (1990: 295). Sobre esta distinção, ver a pesquisa feita por Melo (2002). 
entre dominação e interferência: "é possível haver dominação sem interferência e interferência sem dominação". O liberal busca a não-interferência, mas isso não é suficiente. "Se há dominação mas nenhuma interferência, como no caso do amo que não interfere, apenas o ideal de não-dominação encontrará alguma coisa para denunciar" (Pettit 1997: 23). Em outras palavras, se você não está sofrendo neste momento a interferência de um monarca ilustrado ou benevolente, isso não significa que você não a sofrerá no futuro. Nem os republicanos modernos nem os liberais modernos questionarão isso. No entanto, de acordo com Pettit, os republicanos clássicos não estavam preocupados com a participação, mas com a não-interferência. Assim, conclui ele, "o conceito republicano de liberdade não é um conceito positivo...". ${ }^{9}$ Com essa argumentação, o republicanismo de Pettit perde a maior parte de sua força. Ele não percebe que os republicanos do século XVIII eram, na verdade, uma mistura de republicanos clássicos e liberais modernos, e tira do republicanismo e do conceito de liberdade positiva seu componente mais específico: a participação política.

Charles Taylor adota uma teoria mais afirmativa da liberdade e do republicanismo. Como republicano, ele acredita que os cidadãos busquem o interesse público, mas ele começa por se distanciar de um tipo comum de moral ou republicanismo ingênuo que presume um comportamento altruísta da parte de homens e mulheres. A tradição cívico-humanista à qual ele se sente ligado é "patriótica". E patriotismo tem aqui um sentido preciso - a adesão a um princípio que transcende o egoísmo:

O patriotismo se baseia em uma identificação com os outros em um empreendimento particular comum. Eu não me dedico a defender a liberdade de qualquer um, mas sinto o vínculo de solidariedade com meus compatriotas em nosso empreendimento comum, a expressão comum de nossa dignidade respectiva. (Taylor 1995: 188)

A partir desse conceito, ele afirma que a república é uma sociedade "ligada pelo patriotismo". Enquanto o compromisso moral com o bem-estar de todos os seres humanos geralmente é inoperante, o compromisso patriótico com alguns bens em comum - nosso sistema nacional de saúde, nosso corpo de bombeiros e coisas do gênero - é um exemplo do "vínculo de solidariedade com meus compatriotas em uma república em funcionamento[...] baseado em um sentido de destino compartilhado, onde o próprio compartilhar já é um valor" (Taylor 1995: 192).

${ }^{9}$ Pettit (1997: 27). A primeira frase da citação está no título da seção, não no texto do livro. 
Esse tipo de raciocínio, de acordo com Taylor, é holístico, ou, como eu o chamaria, histórico-dedutivo, não atomístico ou hipotético-dedutivo. A definição de república adotada por Taylor exige tal raciocínio, que tem origem em Aristóteles, enquanto o raciocínio hipotético-dedutivo tem origem em Platão. Se os cidadãos na república têm sentimentos patrióticos é porque vivem em uma comunidade, não em uma sociedade atomística.

A partir desse raciocínio, Taylor conclui que a liberdade é essencialmente positiva: que o cidadão é livre apenas quando tem uma profunda identificação patriótica, e participa ativamente da construção do bemestar comum:

De acordo com a tradição cívico-humanista[...] a condição essencial de um regime livre (não despótico) é que os cidadãos tenham uma identificação patriótica mais profunda[...] O cidadão era 'livre' no sentido de ter direito a uma opinião em decisões no âmbito político que poderiam moldar a vida de todos[...] $\mathrm{O}$ raciocínio subjacente a essa tese é que as disciplinas que, no despotismo, seriam impostas externamente pelo medo têm de ser auto-impostas em sua ausência, e somente a identificação patriótica pode fornecer a motivação para isso.(Taylor 1995: 192-3)

Ao reconciliar o liberalismo moderno com o republicanismo moderno, o conceito de liberdade positiva de Skinner é mais útil do que o de Taylor. Liberais modernos de destaque como Rawls provavelmente se sentiriam mais confortáveis com a visão de Skinner. Outros, como Dworkin, que adota um agressivo conceito negativo de liberdade, rejeitariam ambos. Dworkin (2000: 120) diz claramente que "Liberdade, para mim, é o que é às vezes chamado de liberdade negativa - estar livre de restrições legais - não liberdade ou poder em sentido mais geral”. Por outro lado, ele identifica indiscriminadamente a preocupação com a virtude cívica com o comunitarismo e o conservadorismo. ${ }^{10}$

${ }^{10}$ De acordo com Dworkin (1985: 198): “O conservador presume que o homem bom desejaria ser tratado de acordo com os princípios de um tipo especial de sociedade, que eu chamarei de sociedade virtuosa[...] Eles tratam as vidas de outros membros de sua comunidade como parte de suas próprias vidas." 


\section{O CUSTO DOS DIREITOS}

Assim, no debate da teoria política, liberais e republicanos (e comunitaristas) divergem sobre o conceito de liberdade. No entanto, quando observamos que essa divergência é entre Rawls e Skinner, ou Taylor e Dworkin, percebemos que, embora seja teoricamente forte, é curiosamente fraca em termos políticos. Os quatro eminentes teóricos da política são progressistas, ou "liberais" no sentido norte-americano. Pertencem à esquerda moderna, social-democrata ou social-liberal. Opõem-se fortemente a todos os tipos de conservadorismo - ou seja, à visão política que sistematicamente privilegia a ordem social às expensas da justiça social. Tenho certeza de que todos eles concordariam com a importância de proteger o que eu chamo de direitos republicanos. Mais do que isso, os liberais modernos (mas não os ultra ou neoliberais) compartilham com os republicanos (e com os socialistas democráticos) o reconhecimento da necessidade de combater a desigualdade e fazer valer os direitos sociais.

Os direitos sociais podem ser entendidos como direitos contra outros cidadãos, se pensarmos, por exemplo, sobre os direitos dos trabalhadores com relação a seus patrões. No entanto, quando pensamos sobre os direitos sociais como o direito a uma vida boa, à educação, à cultura, à assistência médica, eles são direitos contra a sociedade civil e o Estado. ${ }^{11}$ Tais direitos não existem independentemente do nível de desenvolvimento econômico de um país; eles se tornaram direitos protegidos nos países desenvolvidos porque tais países tinham condições de fazê-lo. Em cada sociedade, as necessidades sociais são transformadas em direitos sociais quando se dispõe de recursos materiais mínimos para garanti-los. A luta de classes ou, de forma mais moderada, a luta entre a esquerda e a direita em cada país no século passado aconteceu em torno de uma questão central: até que ponto cada Estado-nação deveria e poderia fazer valer os direitos sociais. Se a proteção dos direitos civis e políticos implica custos, a afirmação dos direitos sociais envolve custos adicionais e impostos cor-

11 Estou usando "sociedade civil" em seu sentido clássico, como uma sociedade organizada e ponderada de acordo com os poderes políticos detidos por indivíduos e por grupos, dada sua organização, riqueza ou conhecimento, e não como uma coleção de organizações sem fins lucrativos. Mais recentemente, tendo em vista a crescente importância das organizações públicas não estatais (sem fins lucrativos), este segundo sentido também se tornou habitual. A sociedade civil é freqüentemente pensada em oposição ao Estado. Essa oposição, no entanto, faz sentido apenas quando o governo, que ocupa a liderança do Estado, perde sua legitimidade. Geralmente a sociedade civil e o Estado caminham juntos: o governo representa a sociedade civil dentro do Estado. 
respondentes. Quando dizemos que o Estado cresceu muito no século XX, estamos dizendo na verdade que os impostos aumentaram para financiar as despesas militares (que protegem os direitos civis) e as despesas sociais. Em toda parte os indivíduos ricos e conservadores resistem a pagar maiores impostos, exceto aqueles que protegem os direitos de propriedade. Eles salientam a importância de estimular a iniciativa individual e o trabalho produtivo. No entanto, quando ficou claro que despesas com educação e assistência médica eram também investimentos, tais argumentos perderam muito de seu atrativo. Eles também argumentam contra as despesas relativas ao bem-estar social - sistemas de renda mínima, auxílio-desemprego que encareceriam a mão-de-obra. No entanto, neste caso, o problema é saber que parte do salário deveria ser paga diretamente ao trabalhador, e que parte indiretamente. Quanto maior o nível de educação e de renda, mais aptos estarão os indivíduos a suprir sua própria segurança econômica. Essa é a razão pela qual sistemas de seguridade social garantem uma renda mínima. A pensão complementar de que cada pessoa necessita para sustentar um padrão de vida acima do mínimo seria contratada individualmente junto a fundos de previdência privada.

Os ultra-liberais, e não os liberais, são contra os direitos sociais positivos, argumentando não apenas em termos de liberdade individual mas também em termos de custos: direitos positivos custariam caro. $\mathrm{Na}$ verdade, a fim de garantir direitos civis ou liberais, particularmente direitos de propriedade, também é necessária uma ação governamental positiva, que implica custos, tanto quanto a proteção dos direitos sociais. Holmes e Sunstein, em The Cost of Rights, defendem essa idéia de modo irrefutável. Eles não usam as expressões "Estado republicano" ou "sistema político republicano", mas, quando afirmam que "todos os direitos são positivos" porque todos os direitos envolvem custos e uma ação positiva de parte do Estado, estão descrevendo o Estado republicano: o Estado real que já existe em democracias avançadas, o Estado normativo que tais democracias têm como objetivo. A distinção que fazem entre direitos morais e descritivos corresponde à clássica distinção entre direitos naturais e positivos. Eles observam que: "um interesse se qualifica como um direito quando um sistema jurídico eficaz o trata como tal, usando recursos coletivos para defendê-lo[...] direitos no sentido legal têm "dentes' [...] Quando não estão apoiados pela força da lei, os direitos morais ficam desdentados.” Em outras palavras, o sistema jurídico estabelecido pelo Estado transforma os direitos morais em direitos positivos - em direitos que podem ser defendidos em juízo e devidamente protegidos pelo Estado. Mas nesse sentido, 
argumentam eles, "direitos custam dinheiro: os direitos não podem ser protegidos ou aplicados sem financiamento público" (Holmes e Sunstein 1999: 15-17). Não são só os direitos sociais que custam dinheiro. Todos os direitos, começando pelos direitos civis básicos - direito à liberdade e à propriedade - têm um custo. Os gastos com exército, polícia, com os sistemas penal e judiciário, e com o recolhimento de impostos são gastos do Estado, diretamente relacionados com a necessária proteção dos direitos de propriedade. Os indivíduos podem ir aos tribunais e defender seus direitos somente se tiverem na retaguarda o poder do Estado implícito em tais custos. De acordo com Holmes e Sunstein (1999: 220):

As liberdades privadas têm custos públicos. Isso é verdade não apenas com relação aos direitos à Seguridade Social, Medicare [seguro-saúde] e auxílio-alimentação, mas também aos direitos à propriedade privada, à liberdade de expressão, à imunidade contra abusos policiais, à liberdade contratual, à liberdade de culto, e na verdade com relação a todo o conjunto de direitos característicos da tradição norte-americana.

Os serviços prestados pelo Estado em uma democracia são definidos por lei e, em princípio, são 'gratuitos' - isto é, financiados por impostos. É esse fato que os transforma em direitos, não apenas necessidades, mas isso não significa que não tenham um custo. Significa apenas que a sociedade decidiu repartir os custos. Assim que uma lei especifica um direito, a realização de uma ação ou serviço se torna necessária, e haverá custos envolvidos. Desse modo, o desempenho do governo e seus custos são essenciais para o conceito de um Estado republicano. Ele deve ser eficaz e eficiente na aplicação dos direitos ou na prestação dos serviços relacionados a tais direitos. O aparelho do Estado não deve ser apenas eficaz: deve também ser eficiente. Tendo em vista os limitados recursos fiscais com que pode contar, quanto mais eficiente ele for, mais eficaz poderá ser, porque será capaz de fornecer uma maior quantidade de serviços pelo mesmo custo. É sabido que a legitimidade de um governo depende, entre outras coisas, de sua capacidade de aumentar os impostos, mas nas democracias os governos só são capazes de taxar se os cidadãos puderem perceber que o dinheiro está sendo bem utilizado. Em outras palavras, um Estado merece o nome de "republicano" somente se, além de proteger direitos, inclusive os direitos republicanos, fizer isso de modo eficiente. $\mathrm{O}$ Estado republicano deve estar comprometido com a proteção do 
patrimônio público, não apenas contra a corrupção e formas mais brandas de rentismo, mas também contra a ineficiência. Todos os direitos são democraticamente decididos na constituição e nas leis de cada país, e têm um custo. A hipótese de que os direitos positivos e negativos são distintos porque estes últimos não impõem custos é falsa. O governo tem sempre um papel positivo, que invariavelmente tem um custo. Esse papel positivo pode proteger ou ameaçar a liberdade. Ele ameaça a liberdade no Estado absoluto e a defende no Estado democrático (Holmes e Sunstein 1999: 50). Nas democracias, o que se espera do Estado republicano - sua ação positiva - depende da força que as sociedades têm para defender seus direitos humanos e do âmbito que elas atribuem a tais direitos.

Embora seja legítimo pensar em um Estado liberal e republicano, não devemos encarar com ligeireza, ao conciliar versões moderadas de liberalismo e republicanismo, as diferenças entre as duas ideologias e os perigos envolvidos no liberalismo. O liberalismo pode, com muita facilidade, se tornar excessivamente individualista e levar a um enfraquecimento da república - de um sistema de governo que segue os ideais de autogoverno e de um projeto nacional e cosmopolita. Em seu vigoroso livro sobre a crise atual da democracia norte-americana, Michael Sandel começa por diferenciar a teoria republicana, que afirma que a liberdade depende do envolvimento no autogoverno, da teoria política liberal, que dá ênfase à tolerância e ao respeito pelos direitos individuais. Apesar das ênfases diferentes, ele não teria razão para se opor a uma ou a outra. No entanto, ele observa:

A filosofia política segundo a qual vivemos (nos Estados Unidos) é uma determinada versão da teoria política liberal. Sua idéia central é de que o governo deveria ser neutro em relação às visões morais e religiosas de seus cidadãos[...] Como esse liberalismo afirma a prioridade dos procedimentos justos sobre os objetivos particulares, a vida pública que ele influencia poderia ser denominada república procedimental. (Sandel 1996: 5)

Sandel nos alerta para o fato de que, originalmente, a filosofia pública que guiou os Estados Unidos foi a filosofia republicana - uma filosofia que "exige um conhecimento dos assuntos públicos e um sentido de integração, uma preocupação com o todo, um vínculo moral com a comunidade cujo destino está em jogo". ${ }^{12}$ Posteriormente, no entanto, o

${ }^{12}$ Pocock (1975) escreveu um livro clássico sobre o assunto, mostrando o caráter republicano da Revolução norte-americana. 
liberalismo predominou. Apesar de seus aspectos positivos, a visão liberal negativa da liberdade apresenta um problema crucial: faltam-lhe os recursos cívicos para sustentar o autogoverno. Ele conclui:

Uma república procedimental que bane o argumento moral e religioso do discurso político contribui para o empobrecimento da vida cívica. Deixa também de responder à aspiração de autogoverno; sua imagem dos cidadãos como indivíduos livres e independentes, não tolhidos por vínculos morais ou cívicos que não escolheram, não pode sustentar o espírito público que nos equipa para o autogoverno. (Sandel 1996: 349-50)

Como vemos, Sandel volta aos poderosos argumentos de Taylor. Liberalismo político significa tolerância e pluralismo, não desconfiança e cinismo. No debate público, todos os tipos de argumentos, inclusive morais e religiosos, são legítimos, desde que sejam tolerantes e respeitem as idéias alheias. E valores morais e religiosos são decisivos para unir uma comunidade, dando-lhe um sentido de direção, preparando-a para um Estado republicano e democrático, desde que sejam, como Rawls $(1989,1993)$ insistentemente pede, "razoáveis". Quando o liberalismo clássico ou econômico limita a liberdade a um conceito negativo, além de deixar de ser razoável leva a comunidade para fora da sociedade política.

\section{CONCLUSÃO}

O Estado republicano é um Estado democrático que deriva seu poder e legitimidade do apoio da sociedade civil. Ele garantirá a liberdade negativa, mas sua força dependerá de quanto seus cidadãos, compartilhando uma visão positiva de liberdade, estarão dispostos a participar dos assuntos cívicos. No entanto, é importante lembrar que, para garantir a vida, os direitos de propriedade e os contratos que fundamentam a liberdade, e os direitos sociais que fundamentam a justiça social, o Estado precisa de recursos materiais especificamente, receitas de impostos. Acabamos de ver, com Holmes e Sunstein, que os direitos têm um custo. Portanto, um Estado republicano é um Estado que está democraticamente apto a taxar os cidadãos. Ninguém gosta de ser taxado, mas uma boa medida da força de um Estado e da legitimidade de um governo é sua capacidade de taxar. Não estou afirmando que quanto maior a carga tributária, mais forte e mais republicano será o Estado. Mas estou 
dizendo que um Estado que é incapaz de taxar seus cidadãos adequadamente, enquanto esses mesmos cidadãos exigem dele lei, ordem e serviços sociais, é um Estado fraco: falta-lhe legitimidade política, e ele tenderá a entrar em crise fiscal.

Observamos, em sociedades democráticas avançadas, que o limite máximo para a carga tributária é alto. Não pretendo dizer com isso que, quanto mais avançada e democrática for uma sociedade, maior será sua carga tributária, mas que uma alta carga tributária é uma indicação da força e do caráter republicano do Estado. Não é por acaso que as cargas tributárias médias nos países desenvolvidos são substancialmente maiores do que nos países intermediários, e maiores nestes últimos do que nos países pobres. Não é sem conseqüências que os Estados Unidos têm uma carga tributária de 30 por cento, contra 44 por cento na União Européia e mais do que isso nas democracias sociais mais avançadas do Norte da Europa. Contrariamente a certas perspectivas ingênuas, as democracias desenvolvidas não seguem um único modelo econômico - o modelo de mercado norte-americano. Como já vimos, há pelo menos três outros modelos: o modelo social europeu, o modelo desenvolvimentista asiático ou japonês, e o modelo misto de capitalismo latino-americano. Quando Goodin et al. (1999) descobriram que o modelo "social-democrata" de capitalismo de bem-estar social era superior aos modelos "corporativistas" e "liberais", seria impossível não relacionar esse achado com a maior legitimidade de taxação alcançada pelos Países Baixos e pelos países escandinavos. A onda ideológica neoliberal que começou em meados dos anos 70 foi uma tentativa de limitar os gastos do Estado e a carga tributária. Sua incapacidade de atingir esse objetivo é uma indicação de que os eleitores nas democracias modernas exigem serviços do Estado e estão prontos a pagar por eles. Mas também indica que as sociedades européias avançadas chegaram a uma espécie de limite nessa área. Os direitos sociais, cujos custos devem ser financiados por impostos, já estão basicamente definidos. A carga tributária provavelmente aumentará ainda mais, não em virtude de novos direitos mas porque seus custos - particularmente custos de assistência médica - tenderão a crescer em relação a outros custos, principalmente de produtos manufaturados, à medida que os ganhos de produtividade nas indústrias de serviço forem menores. $\mathrm{O}$ desafio enfrentado pela reforma da gestão pública é precisamente o de aumentar a qualidade e a eficiência dos serviços exigidos, limitando assim a carga tributária.

O Estado republicano que está emergindo é um Estado politicamente forte porque seus dirigentes derivam sua legitimidade das instituições democráticas; é um Estado fiscalmente forte, porque não se deixa endividar 
irresponsavelmente; é um Estado administrativamente forte, porque depois de haver passado pela reforma burocrática, passa atualmente pela reforma da gestão pública. Mas é principalmente um Estado republicano porque conta com cidadãos, com políticos, e com servidores públicos que não olham apenas para seus interesses particulares. Eles olham também para o interesse público. Eles sabem que a globalização é a concorrência generalizada entre os Estados nacionais através de suas empresas, e, por isso, defendem os interesses nacionais de seus concidadãos. Inclusive porque, se não o fizerem, os políticos, os servidores públicos e os cidadãos sabem que serão punidos: os políticos terão uma probabilidade crescente de não serem reeleitos; os servidores públicos perderão prestígio social e poder; e os próprios cidadãos, que imporão essas perdas aos dois tipos de oficiais públicos, sabem que de sua ação cívica depende cada vez mais sua segurança, seu bem-estar, e sua liberdade. E também porque os princípios que regem a política não são os mesmos que regem o mercado. No mercado é razoável que os interesses individuais sejam absolutamente dominantes, na política eles têm que ser necessariamente adoçados pelo interesse público.

LUIZ CARLOS BRESSER-PEREIRA é professor de Economia e Teoria Política da Fundação Getúlio Vargas (SP).

\section{REFERÊNCIAS BIBLIOGRÁFICAS}

BERLIN, I. Two Concepts of Liberty. In: Isaiah Berlin, Four Essays on Liberty. Oxford: Oxford University Press, 1969. Publicado originalmente em 1958.

BIGNOTTO, N. Humanismo Cívico Hoje. In: N. Bignotto, org. Origens do Republicanismo Moderno. Belo Horizonte: Editora UFMG, 2001. p.49-70.

BOBBIO, N.; M. VIROLI Dialogo Intorno alla Repubblica. Roma: Editori Laterza, 2001.

BOCK, G.; Q. SKINNER; M. VIROLI, eds. Machiavelli and Republicanism: Ideas in Context. Cambridge: Cambridge University Press, 1990.

CONSTANT, B. De L'Esprit de Conquête et de l'Usurpation. In: B. Constant (1997) Écrits Politiques. Paris: Gallimard, 1997. Publicado originalmente em 1814.

COSTA, S. As Cores de Ercília. Belo Horizonte: Editora UFMG, 2002.

DAGGER, R. Civic Virtues. Oxford: Oxford University Press, 1997.

DAGNINO, E., ed. Anos 90: Política e Sociedade no Brasil. São Paulo: Editora Brasiliense, 1994.

DWORKIN, R. A Matter of Principle. Cambridge, MA: Harvard University Press, 1985.

DWORKIN, R. Sovereign Virtue. Cambridge, Mass: Harvard University Press, 2000.

ELIAS, N. The Civilizing Process. Oxford: Blackwell Publishers, 1994.

ENCYCLOPÆDIA BRITANNICA, The New Taxation. Chicago: The New Encyclopadia Britannica, Macropadia, 1993, vol.28: 397-421.

GOODIN, R. E.; B. HEADEY; R. MUFFELS; H. DIRVEN The Real Worlds of Welfare Capitalism. Cambridge: Cambridge University Press, 1999.

HOLMES, S.; C. R. SUNSTEIN The Cost of Rights. New York: W. W. Norton, 1999.

JANINE RIBEIRO, R. A Política como Espetáculo. In: Evelina Dagnino, ed. Anos 90: 
Política e Sociedade no Brasil. São Paulo: Editora Brasiliense, 1994.

LOCKE, J. Second Treatise of Government. Cambridge: Hackett Publishing Co., 1980. Publicado originalmente em 1690.

MELO, M.A. Republicanismo, Liberalismo e Racionalidade. Lua Nova - Revista de Cultura Política, $\mathrm{n}^{\circ} .55-56,2002$. p. 57-84.

PETTIT, P. Republicanism. Oxford: Oxford University Press, 1997.

POCOCK, J. G. A. (1975) The Machiavellian Moment: Florentine Political Theory and the Atlantic Republican Tradition. Princeton, NJ: Princeton University Press, 1975.

RAWLS, J. (1989) "The Domain of the Political and Overlapping Consensus". In: Copp, Hampton, and Roemer, eds. (1993: 245-269). Originalmente publicado na New York University Law Review, 2 de Maio de 1989: 233-55.

RAWLS, J. Political Liberalism. New York, Columbia University Press, 1993.

SANDEL, M. J. Democracy's Discontent: America in Search of a Public Philosophy. Cambridge, MA: Harvard University Press, 1996.

SKINNER, Q. The Foundations of Modern Political Thought. Cambridge: Cambridge University Press, 1978.

SKINNER, Q. The Republican Ideal of Liberty. In: Bock, Skinner, and Viroli, eds. Machiavelli and Republicanism: Ideas in Context. Cambridge: Cambridge University Press, 1990. p. 293-309.

SKINNER, Q. (1998) Liberty Before Liberalism. Cambridge: Cambridge University Press, 1998.

SMEND, R. Sobre el Problema de lo Público y la 'Cosa Publica'. In: R. SMEND Constitución y Derecho Constitucional. Madrid: Centro de Estudios Constitucionales, 1985. Ensaio originalmente publicado em alemão em 1934.

SMITH, A. The Wealth of Nations. London: Everyman's Library, 1960. Primeira edição, 1776.

TAYLOR, C. Philosophical Arguments. Cambridge: Cambridge University Press, 1995. 